\title{
Isolation and characterization of fibronectin- $\alpha_{1}$-microglobulin complex in rat plasma
}

\author{
Cecilia FALKENBERG, ${ }^{\star} \ddagger$ Jan J. ENGHILD, $\dagger$ Ida B. THøGERSEN, $\dagger$ Guy SALVESEN $\dagger$ and Bo ÅKERSTRÖM ${ }^{\star}$ \\ *Department of Medical and Physiological Chemistry, University of Lund, P.0. Box 94, S-221 00 Lund, Sweden, and the †Department of Pathology, \\ Duke University Medical Center, Durham, NC 27710, U.S.A.
}

\begin{abstract}
Molecules containing the $28 \mathrm{kDa}$ immunoregulatory protein $\alpha_{1^{-}}$ microglobulin $\left(\alpha_{1}-\mathrm{m}\right)$, also known as protein $\mathrm{HC}$, were isolated from rat plasma or serum by immunoaffinity chromatography. Three molecular species were distinguished on the basis of nondenaturing PAGE. Two of these have been described previously: uncomplexed $\alpha_{1}-\mathrm{m}$, and the complex of $\alpha_{1}$-m with $\alpha_{1}$-inhibitor-3. The third species was analysed by denaturing PAGE, immunoblotting, proteinase digestion and $\mathrm{N}$-terminal-sequence analyses, and shown to consist of a complex between $\alpha_{1}-\mathrm{m}$ and fibronectin. This complex, with a mass of about $560 \mathrm{kDa}$, was resistant to dissociation in the presence of denaturants, but not in the presence of reducing agents in combination with denaturants, and we conclude that the two components are linked by disulphide bonds. About $60 \%$ of the total detectable plasma $\alpha_{1}$ $\mathrm{m}$ exists as high-molecular-mass complexes distributed approxi-
\end{abstract}

mately evenly between fibronectin and $\alpha_{1}$-inhibitor-3. Immunochemical analyses were used to determine the proportion of the total plasma pools of fibronectin and $\alpha_{1}$-inhibitor- 3 that circulate in complex with $\alpha_{1}-\mathrm{m}$. About 3-7\% of the total plasma fibronectin from three different rat strains contained $\alpha_{1}-\mathrm{m}$, whereas $0.3-0.8 \%$ of the total plasma $\alpha_{1}$-inhibitor-3 contained $\alpha_{1}-\mathrm{m}$. Complexes were found at similar levels in plasma and serum, indicating that coagulation is not responsible for complex formation. Moreover, immunochemical analyses of human plasma revealed small amounts of $\alpha_{1}-\mathrm{m}$ in complex with fibronectin and $\alpha_{2}$-macroglobulin (an $\alpha_{1}$-inhibitor-3 homologue). The existence of a complex between $\alpha_{1}-\mathrm{m}$ and fibronectin in rats and humans suggests a mechanism for the incorporation of the immunoregulatory molecule $\alpha_{1}-\mathrm{m}$ into the extracellular matrix.

\section{INTRODUCTION}

$\alpha_{1}$-Microglobulin $\left(\alpha_{1}-\mathrm{m}\right)$, a $26-28 \mathrm{kDa}$ plasma protein first isolated from human urine (Ekström et al., 1975; Ekström and Berggård, 1977), is involved in the immune response of the organism (for a review, see Åkerström and Lögdberg, 1990). It has regulatory, mainly suppressive, effects on lymphocytes and granulocytes (Lögdberg and Åkerström, 1981; Mendez et al., 1986), and receptors for $\alpha_{1}-\mathrm{m}$ have been identified on white blood cells (Fernandez-Luna et al., 1988; Babiker-Mohamed et al., 1990). It is synthesized in rat hepatocytes, and secretion from liver cells is stimulated by cytokines activated during the immune response and inflammation (Pierzchalski et al., 1992). The gene for $\alpha_{1}$-m also encodes bikunin, a Kunitz-type protease inhibitor (Diarra-Mehrpour et al., 1990; Vetr and Gebhard, 1990). A precursor protein, $\alpha_{1}-\mathrm{m}$-bikunin, is expressed by the gene and cleaved in the trans-Golgi network, and free $\alpha_{1}-\mathrm{m}$ is released from the liver cells (Kaumeyer et al., 1986; Bratt et al., 1993). In the blood, however, only about $50 \%$ of $\alpha_{1}-\mathrm{m}$ is found in the free form, and the remaining portion is found as high-molecularmass complexed forms (Ekström et al., 1975; Tejler and Grubb, 1976).

It is not yet known why $\alpha_{1}-\mathrm{m}$ and bikunin are encoded by the same mRNA. No functional connection between the two proteins has so far been reported, and no circulating $\alpha_{1}-\mathrm{m}$-bikunin form has been found. Instead, $\alpha_{1}-\mathrm{m}$ complexes formed with human albumin (Tejler and Grubb, 1976), human IgA (Grubb et al., 1986) and the rat $\alpha$-macroglobulin $\alpha_{1}$-inhibitor-3 $\left(\alpha_{1}-I_{3}\right)$ (Falkenberg et al., 1990) have been demonstrated. Bikunin, on the other hand, is found as a constituent of the plasma proteins inter- $\alpha$-inhibitor (Salier, 1990), pre- $\alpha$-inhibitor (Enghild et al., 1989) and inter- $\alpha$-like inhibitor (Enghild et al., 1993).

In the pursuit of a molecular species containing both $\alpha_{1}-\mathrm{m}$ and bikunin, we studied the high-molecular-mass forms of rat plasma $\alpha_{1}-\mathrm{m}$. We found no evidence for the presence of this species, but $\alpha_{1}-\mathrm{m}$ was instead found to be linked by disulphide bonds to fibronectin, a cell-adhesive extracellular-matrix glycoprotein which occurs in a soluble form in plasma (for a review, see Yamada, 1991). The complex was isolated and found to be circulating in normal rat plasma at similar levels to the $\alpha_{1}-\mathrm{m}$ $\alpha_{1}-I_{3}$ complex.

\section{EXPERIMENTAL}

\section{Materials}

Frozen rat plasma was obtained from Pel-Freeze Biologicals (U.S.A.). Fresh rat plasma (using EDTA) or serum was drawn from Sprague-Dawley, Wistar-Furth or Copenhagen rats (B\&K Universal AB, Sweden) which had been anaesthesized with ether. In some experiments blood was drawn directly into a solution of $N$-ethylmaleimide to a final concentration of $10 \mathrm{mM}$. Human plasma was obtained from a healthy blood donor. Monoclonal mouse anti- $\alpha_{1}-\mathrm{m}, \mathrm{BN} 11.2$, binds to human and rabbit $\alpha_{1}-\mathrm{m}$, BN11.3, BN11.7 and BN11.10 to rat and human $\alpha_{1}-\mathrm{m}$, and BN11.6 to rat and rabbit $\alpha_{1}$-m (Babiker-Mohamed et al., 1991). Rat serum $28 \mathrm{kDa} \alpha_{1}-\mathrm{m}$ (Falkenberg et al., 1990) and human urinary $\alpha_{1}-\mathrm{m}$ (Ekström and Berggård, 1977) were isolated as described. $\alpha_{1}-\mathrm{I}_{3}$ was purified from rat plasma as reported earlier (Enghild et al., 1989). Human fibronectin was purchased from Sigma Chemical Co. and also generously provided by Dr. Bo

Abbreviations used: $\alpha_{1}-\mathrm{m}, \alpha_{1}$-microglobulin; $\alpha_{1}-\mathrm{I}_{3}, \alpha_{1}$-inhibitor-3; PVDF, poly(vinylidene difluoride); V8 proteinase, Staphylococcus aureus V8 proteinase.

$\ddagger$ To whom correspondence should be addressed. 
Cederholm (Department of Nephrology, University of Lund, Sweden). Rat fibronectin was bought from Sigma and Staphylococcus aureus V8 proteinase (V8 proteinase) from BoehringerMannheim. Rabbit antisera against rat $\alpha_{1}-\mathrm{I}_{3}$, and against human and rat $\alpha_{1}-\mathrm{m}$, and goat antisera against human $\alpha_{1}-\mathrm{m}$ and rabbit $\mathrm{IgG}$, were prepared and characterized in this laboratory, and purified by ion-exchange chromatography (Nilson et al., 1986). Rabbit anti-(rat fibronectin) antibody was from CalbiochemBehring and chicken anti-(human fibronectin) and rabbit anti(chicken IgG) antibodies were from Immunsystem AB (Sweden). Rabbit anti-(human fibronectin) and rabbit anti-(mouse IgG) were obtained from Dakopatts, Denmark.

\section{Chromatography methods}

Immunosorbent chromatography was performed using monoclonal anti- $\alpha_{1}-\mathrm{m}$ antibodies BN11.3 and BN11.10 immobilized to Affi-gel Hz (40 mg/2 ml of gel), according to the manufacturer's instructions (Bio-Rad Laboratories, Richmond, CA, U.S.A.). Plasma samples $(5 \mathrm{ml})$ from Sprague-Dawley rats were centrifuged for $10 \mathrm{~min}$ at $10000 \mathrm{~g}$. After adding EDTA to a final concentration of $10 \mathrm{mM}$, the plasma was filtered through a $0.22 \mu \mathrm{m}$ pore diam. membrane, diluted with $5 \mathrm{ml}$ of $20 \mathrm{mM}$ Tris/ $\mathrm{HCl}$, pH 8.0, containing $0.15 \mathrm{M} \mathrm{NaCl}, 0.02 \% \mathrm{NaN}_{3}$ and $10 \mathrm{mM}$ EDTA (Tris/ $\mathrm{NaCl} / \mathrm{NaN}_{3} /$ EDTA), and finally applied to the affinity column which had been equilibrated in the Tris $/ \mathrm{NaCl} / \mathrm{NaN}_{3} /$ EDTA buffer. After application of the sample and washing with Tris $/ \mathrm{NaCl} / \mathrm{NaN}_{3} /$ EDTA buffer, the column was eluted with $4 \mathrm{M} \mathrm{MgCl}$ and the eluate immediately dialysed against $20 \mathrm{mM}$ Tris $/ \mathrm{HCl}, \mathrm{pH} 8.0$, containing $0.15 \mathrm{M} \mathrm{NaCl}$ and $0.02 \% \mathrm{NaN}_{3}$ (Tris/ $\mathrm{NaCl} / \mathrm{NaN}_{3}$ ). The eluates from a total of $15 \mathrm{ml}$ of rat plasma samples were pooled and concentrated by ultrafiltration and then applied to a column $(100 \mathrm{~cm} \times 1.4 \mathrm{~cm})$ packed with Sephacryl S-300 (Pharmacia-LKB Biotechnology $\mathrm{AB}$, Sweden). The column was equilibrated in, and eluted with, Tris $/ \mathrm{NaCl} / \mathrm{NaN}_{3}$ buffer, and had been calibrated with Blue Dextran (Pharmacia-LKB Biotechnology AB), human IgG (Sigma), ovalbumin (Sigma) and dinitrophenylalanine (Sigma).

Comparative studies on plasma and serum from different rat strains were performed as described above with a few changes. Samples $(2 \mathrm{ml})$ of plasma or serum were applied to the Affi-gelcoupled monoclonal mouse anti- $\alpha_{1}-\mathrm{m}$. The column was eluted with $0.1 \mathrm{M}$ glycine $/ \mathrm{HCl}, \mathrm{pH} 2.5$, and the acidic fractions were immediately neutralized by the addition of $1 \mathrm{M}$ Tris/ $\mathrm{HCl}, \mathrm{pH} 8.0$. When serum was applied, EDTA was excluded from the sample and dilution buffers. $\alpha_{1}$-m-containing fractions were pooled and concentrated.

The following purification protocol was carried out before amino acid sequence analysis. Rat plasma (180 ml, Pel-Freeze Biologicals) was centrifuged for $30 \mathrm{~min}$ at $10000 \mathrm{~g}$, and adjusted to $20 \mathrm{mM}$ sodium phosphate, $\mathrm{pH} 7.0,10 \mathrm{mM}$ EDTA and $0.5 \mathrm{M}$ $\mathrm{NaCl}$ in a total volume of $540 \mathrm{ml}$. The plasma was then filtered through a $0.22 \mu \mathrm{m}$ pore diam. membrane, and Nonidet P-40 (NP-40) was added to $1 \%$ before application to the column ( $2 \mathrm{ml})$ packed with Sepharose-coupled monoclonal anti- $\alpha_{1}-\mathrm{m}$ antibodies BN11.3 and BN11.6. The column was washed with the dilution buffer, and then eluted with $4 \mathrm{M} \mathrm{MgCl}_{2}$. The eluted sample was dialysed against $50 \mathrm{mM}$ Tris $/ \mathrm{HCl} / 50 \mathrm{mM} \mathrm{NaCl}$, $\mathrm{pH}$ 7.4. Following concentration the sample was further purified by anion-exchange chromatography employing a Pharmacia f.p.l.c. system and a $1 \mathrm{ml}$ Mono Q column. The elution from this column was done with a linear gradient from 0 to $1.0 \mathrm{M} \mathrm{NaCl}$ in $50 \mathrm{mM}$ Tris/ $\mathrm{HCl}, \mathrm{pH} 7.4$.

Human plasma $(1 \mathrm{ml})$ was subjected to affinity chromatography on a BN11.2 anti- $\left(\alpha_{1}-\mathrm{m}\right)$ Affi-gel Hz column $(80 \mathrm{mg} / 2 \mathrm{ml})$.
The column was eluted with $0.1 \mathrm{M}$ glycine $/ \mathrm{HCl}, \mathrm{pH} 2.5$, acidic fractions were immediately neutralized, and $\alpha_{1}$-m-containing fractions in the eluate pooled and concentrated by ultrafiltration as described for rat plasma.

\section{PAGE analysis}

PAGE in the presence of SDS, with or without 2-mercaptoethanol in the sample buffer, was performed according to the method of Laemmli (1970). For molecular-mass standards we used high-molecular-mass Rainbow markers from Amersham International (Amersham, Bucks., U.K.). The procedure for performing non-denaturing pore-limit PAGE in 4-20\% gradient gels was modified from the description of Manwell (1977). The gels were run for $17 \mathrm{~h}$ at $135 \mathrm{~V}$ with continuous circulation of the $89 \mathrm{mM}$ Tris/boric acid, pH 8.34, 2 mM EDTA (Tris/EDTA/ boric acid buffer) between the upper and lower buffer reservoirs. Pharmacia standards, thyroglobulin $(669 \mathrm{kDa})$, ferritin $(440 \mathrm{kDa})$, catalase $(232 \mathrm{kDa})$, lactate dehydrogenase $(140 \mathrm{kDa})$ and albumin $(67 \mathrm{kDa})$, were used as markers for molecular masses. Some samples were first separated by the non-denaturing pore-limit PAGE system and then as a second step applied to SDS/PAGE, according to Enghild et al. (1989). After completed pore-limit PAGE, the gels were stained for $5 \mathrm{~min}$, rinsed in distilled water, and protein bands cut out. SDS-containing sample buffer $(60 \mu \mathrm{l})$, with or without 2-mercaptoethanol, and $1 \mu \mathrm{l}$ of $1 \mathrm{M} \mathrm{NaOH}$ were added to the gel slices, which then were incubated for $30 \mathrm{~min}$ at $37^{\circ} \mathrm{C}$. The gel slices were then transferred to the sample application wells of an SDS/PAGE gel and electrophoresis was performed as usual.

\section{Western-blot analysis}

Proteins separated by SDS/PAGE or pore-limit PAGE were transferred to poly(vinylidene difluoride) (PVDF) membranes (Immobilon, Millipore, U.S.A.) as described (Madsudaira, 1987). The membranes were incubated with different rabbit or mouse antibodies $(10 \mathrm{mg} / \mathrm{l})$, and probed with ${ }^{125} \mathrm{I}$-labelled goat anti(rabbit IgG) or rabbit anti-(mouse IgG) (approx. $10 \mathrm{kBq} / \mathrm{ml}$ ). For a detailed description of the procedure, see Falkenberg et al. (1992). After washing and drying, the membranes were autoradiographed or developed using a Fujix BAS 2000 Bio-imaging analyser (Fuji Films Co., Japan).

\section{Radiolabelling of proteins}

Proteins were labelled with ${ }^{125}$ I (Bio-Nuclear AB, Sweden) by the chloramine-T method (Greenwood et al., 1963) to a specific radioactivity of between 0.3 and $1 \mathrm{MBq} / \mu \mathrm{g}$ of protein.

\section{Determination of specific protein concentrations}

Specific rat or human $\alpha_{1}$-m concentrations were determined by r.i.a. as described (Åkerström, 1985). Specific concentrations of rat fibronectin or $\alpha_{1}-I_{3}$ were measured by solid-phase r.i.a. Microtitre plate wells (Falcon 3912, Becton Dickinson and Co., U.S.A.) were coated by incubation overnight at room temperature with $50 \mu \mathrm{l}$ of rabbit anti-(rat fibronectin) serum (diluted 20000-fold in PBS: $8 \mathrm{mM}$ sodium phosphate, $1.5 \mathrm{mM}$ potassium phosphate, $\mathrm{pH} 7.4,0.12 \mathrm{M} \mathrm{NaCl}, 2.7 \mathrm{mM} \mathrm{KCl}$ ) or rabbit anti(rat $\left.\alpha_{1}-I_{3}\right) \operatorname{IgG}(3 \mathrm{mg} / \mathrm{l})$. The wells were washed three times with $0.15 \mathrm{M} \mathrm{NaCl} / 0.05 \%$ Tween-20, and incubated overnight at room temperature with $50 \mu \mathrm{l}$ of a mixture of radioiodinated rat fibronectin or $\alpha_{1}-\mathrm{I}_{3}(20$ or $40 \mathrm{kBq} / \mathrm{ml}$ in PBS $/ 0.05 \%$ Tween-20) and standard or unknown amounts of unlabelled rat fibronectin or $\alpha_{1}-I_{3}$. This mixture had been preincubated overnight at room 
temperature in a total volume of $200 \mu \mathrm{l}$, using a fibronectin or $\alpha_{1}$ $I_{3}$ concentration range of 4-2000 $\mu \mathrm{g} / \mathrm{l}$. After a final wash, each well was counted separately for radioactivity.

The relative contents of fibronectin or $\alpha_{1}-\mathrm{I}_{3}$ in affinity- or gelchromatography fractions were also followed by solid-phase r.i.a. Briefly, the microtitre plate wells were coated with proteins by incubating overnight with $50 \mu \mathrm{l}$ of the diluted chromatographic fractions, washed and incubated overnight with $50 \mu \mathrm{l}$ of antibody (diluted to $50 \mathrm{mg} / \mathrm{l}$ ), washed again and incubated for $2 \mathrm{~h}$ with ${ }^{125} \mathrm{I}$-labelled goat anti-(rabbit $\left.\mathrm{IgG}\right)(20 \mathrm{kBq} / \mathrm{ml})$. The elution volumes of the $\alpha_{1}$-m-fibronectin and $\alpha_{1}-\mathrm{m}-\alpha_{1}-\mathrm{I}_{3}$ complexes, estimated from the relative contents of fibronectin and $\alpha_{1}-\mathrm{I}_{3}$ respectively, were identical using different dilutions (10-, 50 - or 200 -fold) of the chromatographic fractions for coating of the microtitre plate wells.

\section{Binding between $\alpha_{1}-m$ and fibronectin}

The binding between $\alpha_{1}-\mathrm{m}$ and fibronectin was studied by solidphase r.i.a. The wells were coated with different concentrations of rat or human fibronectin, washed and incubated with ${ }^{125} \mathrm{I}-$ labelled rat or human low-molecular-mass $\alpha_{1}-\mathrm{m}(0.1 \mathrm{MBq} / \mathrm{ml})$ in PBS and $0.05 \%$ Tween-20, with or without the additions of $6 \mathrm{M}$ guanidine hydrochloride, $2 \mathrm{M}, 4 \mathrm{M}$, or $6 \mathrm{M}$ urea and/or $1 \mathrm{mM}$ 2-mercaptoethanol. Alternatively, the wells were coated with rat low-molecular-mass $\alpha_{1}-\mathrm{m}$, washed and then incubated with ${ }^{125} \mathrm{I}$ labelled rat fibronectin.

\section{Preparing samples for amino-acid-sequence analysis}

Rat serum samples were purified by anti- $\alpha_{1}-m$ affinity chromatography and anion-exchange chromatography as described above. Individual fractions from the latter chromatography were separated by SDS/PAGE using the buffer system described by Bury (1981), and bands of interest were electro-eluted from the gels according to Hunkapiller et al. (1983). The electro-eluted proteins were then digested in $\mathrm{NH}_{4} \mathrm{HCO}_{3}$ with $\mathrm{V} 8$ proteinase for $4 \mathrm{~h}$ at $37^{\circ} \mathrm{C}$ employing an enzyme: substrate ratio of $1: 50(\mathrm{w} / \mathrm{w})$. The digest was made $1 \mathrm{M}$ in guanidine hydrochloride and the peptides were separated in an Applied Biosystems Model 130A h.p.l.c. system using an Ultrasphere $C 8$ column $(2.1 \mathrm{~cm} \times 25 \mathrm{~cm}$, Beckman, U.S.A), eluting with $0.1 \%$ trifluoroacetic acid and a linear gradient of $0-90 \% \quad \mathrm{CH}_{3} \mathrm{CN}$. The absorbance was monitored at $220 \mathrm{~nm}$ and the peptides were collected manually. The peptides were analysed by Edman degradation and the resulting sequences compared with the Protein Identification Resource Database (National Biomedical Research Foundation) (PIR, NRBF).

\section{Amino-acid-sequence analysis}

Automated Edman degradation was carried out in an Applied Biosystems Model 477A sequencer with on-line phenylthiohydantoin analysis using an Applied Biosystems Model 120 h.p.l.c. system. The samples were applied to peptide-sample support discs and sequenced employing the modified cycles PIBGN and PI-1 recommended by Porton Instruments.

\section{RESULTS}

\section{Isolation of an $\alpha_{1}$-m-fibronectin complex}

The initial aim of this work was to analyse high-molecular-mass complexes of $\alpha_{1}-\mathrm{m}$ in rat plasma, including the previously discovered $\alpha_{1}-\mathrm{m}-\alpha_{1}-\mathrm{I}_{3}$ complex (Falkenberg et al., 1990). All $\alpha_{1}-\mathrm{m}-$ containing molecules were isolated from rat plasma by affinity chromatography on immobilized monoclonal anti- $\alpha_{1}-\mathrm{m}$ anti- bodies. Bound proteins were eluted with $4 \mathrm{M} \mathrm{MgCl}_{2}$, separated by Mono $Q$ ion-exchange chromatography and SDS/PAGE (results not shown). Protein bands with a molecular mass of around $220 \mathrm{kDa}$ were eluted from the polyacrylamide gels, digested by $\mathrm{V} 8$ proteinase and the resulting peptides separated by reversed-phase h.p.l.c. Isolated peptides were then submitted to $\mathrm{N}$-terminal amino-acid-sequence analysis. The resulting sequences from three peptides are shown in Figure 1. All three

\author{
1 ANPDTGVLTV (residues 1151-1160) \\ 2 GLNQPTDDSCFDPY (residues 2255-2268) \\ 3 LTNLLVRYSPVKNEE (residues 1353-1367)
}

\section{Figure 1 Amino acid sequences of peptides derived from a rat plasma $\alpha_{1}-\mathrm{m}$ complex}

Rat plasma was subjected to anti- $\alpha_{1}-\mathrm{m}$ affinity chromatography, Mono Q-Sepharose anionexchange chromatography, and SDS/PAGE in the presence of mercaptoethanol. A band around $220 \mathrm{kDa}$ was electro-eluted (Hunkapiller et al., 1983), digested with V8 proteinase and separated by h.p.I.c. on a reversed-phase $\mathrm{C}$ column. Three peaks were subjected to $\mathrm{N}$-terminal amino-acid-sequence analysis. After homology searches, all three sequences were found to be identical with rat fibronectin internal amino acid sequences at the positions shown in the Figure.

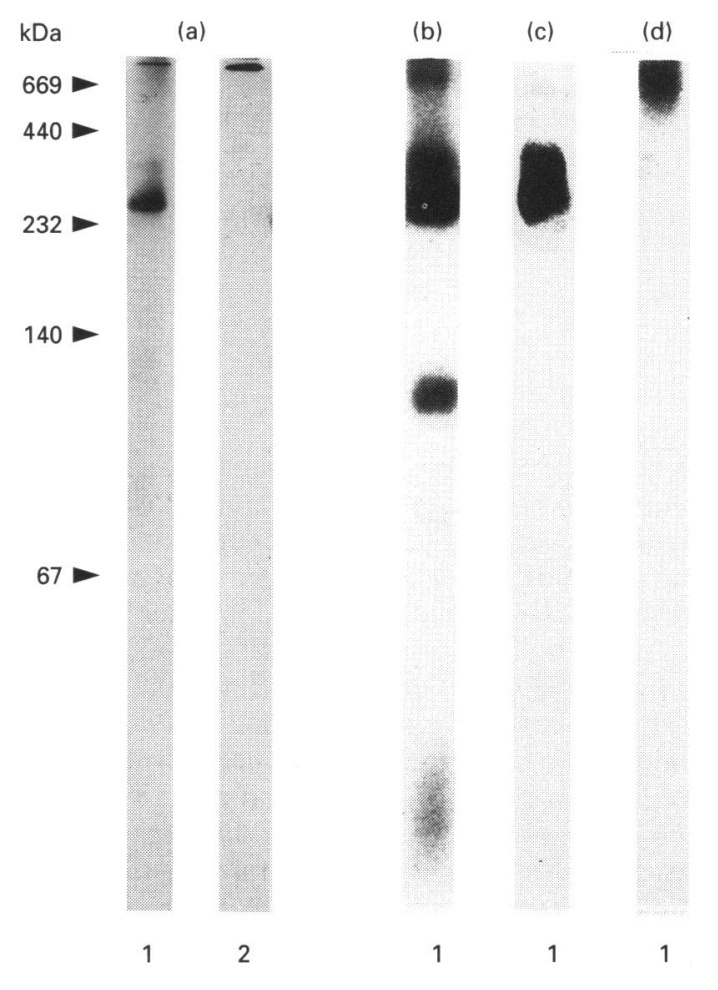

\section{Figure 2 Pore-limit gel electrophoresis of $\alpha_{1}$-m-containing proteins in rat plasma}

Rat plasma was subjected to affinity chromatography on an anti- $\alpha_{1}-\mathrm{m}$ Affi-gel column. The proteins eluted with $4 \mathrm{M} \mathrm{MgCl}_{2}$ were separated under non-denaturing conditions by pore-limit PAGE (4-20\% polyacrylamide), and stained for protein (a). In lane 1, approx. $5 \mu \mathrm{g}$ of proteins of the anti- $\alpha_{1}-\mathrm{m}$ eluate were applied, and in lane 2,10 $\mu \mathrm{g}$ of rat fibronectin. Lane 1 was also transferred to PVDF membranes $(\boldsymbol{b}-\mathbf{d})$. The membranes were incubated with monoclonal anti$\alpha_{1}-m$ antibodies (b), rabbit ${ }^{*}$ anti-(rat $\alpha_{1}-I_{3}$ ) antibodies (c) or rabbit anti-(rat fibronectin) antibodies (d), and then probed with ${ }^{125}$-labelled rabbit anti-(mouse $\lg G$ ) (b) or ${ }^{125}$-labelled goat anti-(rabbit lgG) (c and d). Autoradiography was performed at $-30^{\circ} \mathrm{C}$. Molecular-mass markers are shown in $\mathrm{kDa}$. 
(a)

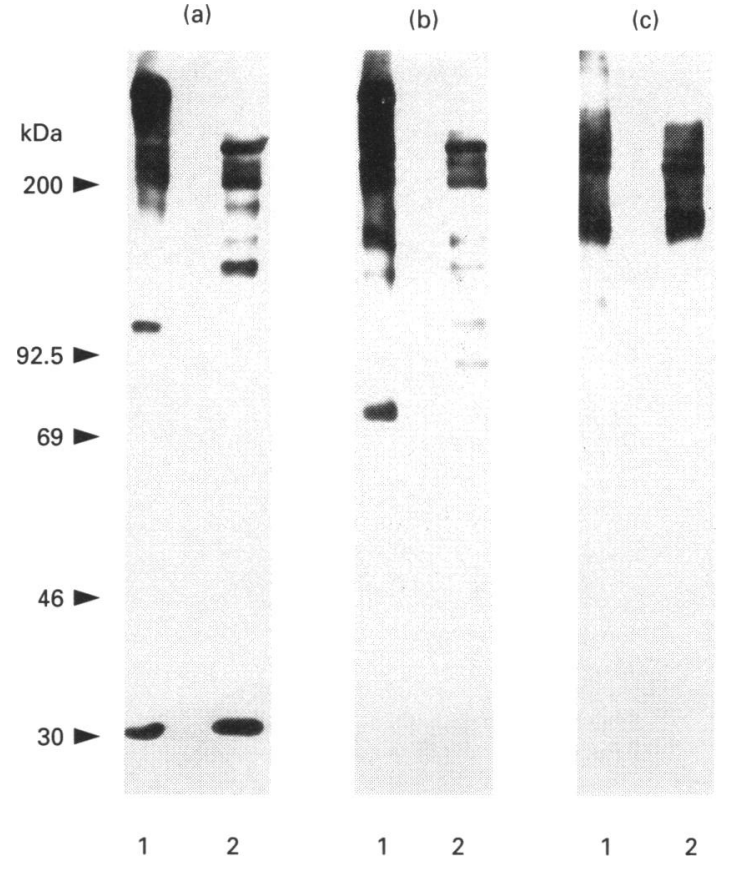

Figure 3 SDS/PAGE of $\alpha_{1}$-m-containing proteins in rat plasma

Rat plasma was subjected to affinity chromatography on an anti- $\alpha_{1}-m$ Affi-gel column. The proteins eluted with $4 \mathrm{M} \mathrm{MgCl}$, were separated by SDS/PAGE $(8.5 \%$ polyacrylamide, $2.5 \%$ bisacrylamide) in the absence (lane 1) or presence (lane 2) of mercaptoethanol, and were transferred to PVDF membranes (a-c). The membranes were incubated with monoclonal anti$\alpha_{1}-\mathrm{m}$ antibodies (a), rabbit anti-(rat $\left.\alpha_{1}-I_{3}\right)$ antibodies (b) or rabbit anti-(rat fibronectin) antibodies (c), and then probed with ${ }^{125}$-labelled rabbit anti-(mouse $\lg G$ ) (a) or ${ }^{125}$-labelled goat anti-(rabbit lgG) (b and $\mathbf{c})$. The radioactivity on the membranes was analysed by digital imaging in a Fujix Bio-imaging analyser.

sequences were identical with sequences in rat fibronectin [see for instance Hynes (1990)].

The proteins which were eluted from the anti- $\alpha_{1}-\mathrm{m}$ column were subjected to pore-limit PAGE (Figure 2), which separates native molecules according to size. Protein staining of the anti$\alpha_{1}-\mathrm{m}$ eluate (Figure $2 \mathrm{a}$, lane 1 ) revealed two strongly stained bands migrating as 795 and $250 \mathrm{kDa}$. Immunoblotting demonstrated $\alpha_{1}-\mathrm{m}$ in both of these bands (Figure 2b), $\alpha_{1}-\mathrm{I}_{3}$ in the $250 \mathrm{kDa}$ band (Figure 2c) and fibronectin in the $795 \mathrm{kDa}$ band (Figure 2d). The fibronectin $/ \alpha_{1}-\mathrm{m}$-containing $795 \mathrm{kDa}$ band was slightly larger than the purified rat fibronectin which was applied in Figure 2(a) (lane 2). A $115 \mathrm{kDa}$ band and an heterogeneous 20-30 kDa band, not visible by protein staining, were seen after blotting with anti- $\alpha_{1}-\mathrm{m}$. The latter migrated as free, monomeric $\alpha_{1}-m$ (results not shown), and most likely represents free plasma $\alpha_{1}-\mathrm{m}$. These results thus suggest that an $\alpha_{1}-\mathrm{m}$-fibronectin complex, with a molecular mass slightly larger than free fibronectin, is present in rat plasma, as well as free $\alpha_{1}-\mathrm{m}$ and the previously described $\alpha_{1}-\mathrm{m}-\alpha_{1}-\mathrm{I}_{3}$ complex (Falkenberg et al., 1990).

The mass of the $\alpha_{1}-\mathrm{m}$-fibronectin complex was also estimated by gel chromatography. The material which was eluted from the anti- $\alpha_{1}-\mathrm{m}$ affinity column was applied to a Sephacryl S-300 column (not shown). The fractions were analysed for total protein by u.v.-light absorbance and SDS/PAGE, and for reactivity with anti-fibronectin and anti- $\alpha_{1}-I_{3}$ by solid-phase r.i.a. The fibronectin and $\alpha_{1}-I_{3}$ complexes eluted as two incompletely separated peaks, with the top fractions appearing around 560 and $300 \mathrm{kDa}$ respectively.

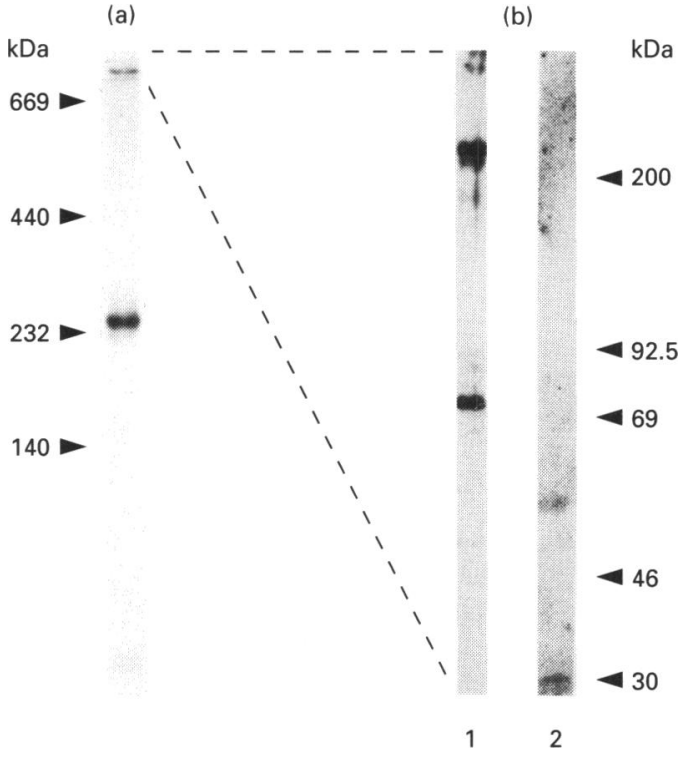

Figure 4 Separation of $\alpha_{1}$-m-containing proteins in rat plasma by nondenaturing pore-limit PAGE, followed by SDS/PAGE

Rat plasma was subjected to affinity chromatography on an anti- $\alpha_{1}-\mathrm{m}$ Affi-gel column. The proteins eluted with $4 \mathrm{M} \mathrm{MgCl}_{2}$ were separated under non-denaturing, non-reducing conditions by pore-limit PAGE (see legend to Figure 2), and stained (a). A high-molecular-mass antifibronectin-binding band, identified in a separate experiment by immunoblotting as described in the legend to Figure 2, was cut out from two equivalent lanes. After equilibration with buffer containing SDS (lane 1) or buffer containing mercaptoethanol and SDS (lane 2), the gel slices were applied to SDS/PAGE ( $8.5 \%$ polyacrylamide, $2.5 \%$ bis-acrylamide). After electrophoresis, the gel was blotted on to PVDF membranes (b), which were incubated with a mixture of three monoclonal anti- $\alpha_{1}-\mathrm{m}$ antibodies $(30 \mathrm{mg} / \mathrm{l})$, and probed with ${ }^{125}$-labelled rabbit anti-(mouse $\lg G)$.

\section{Disulphide bond formation between $\alpha_{1}-\mathrm{m}$ and fibronectin}

The binding between $\alpha_{1}-\mathrm{m}$ and its complexing partners was studied by SDS/PAGE under non-reducing and reducing conditions and immunoblotting of the eluate from the affinity chromatography column (Figure 3 ). In the absence of reducing agents, most of the $\alpha_{1}-\mathrm{m}$ was found in high-molecular-mass bands above $200 \mathrm{kDa}$ (Figure 3a, lane 1), suggesting that the binding between $\alpha_{1}-\mathrm{m}$ and fibronectin or $\alpha_{1}-\mathrm{I}_{3}$ is mostly covalent. The presence of small amounts of free $\alpha_{1}-\mathrm{m}$, however, indicate that non-covalent forces may be involved to some extent, though base-catalysed hydrolysis of disulphide bonds cannot be ruled out completely. More of the free $28 \mathrm{kDa} \alpha_{1}-\mathrm{m}$ was liberated in the presence of reducing agents (Figure 3a, lane 2), indicating that disulphide bonds are partly responsible for the covalent binding between $\alpha_{1}-\mathrm{m}$ and its complex partners. However, blotting with anti- $\alpha_{1}-\mathrm{I}_{3}$ yielded a similar pattern to blotting with anti-fibronectin, both under non-reducing and reducing conditions (Figures $3 \mathrm{~b}$ and $3 \mathrm{c}$ respectively), making it impossible to distinguish between the $\alpha_{1}-\mathrm{I}_{3}$ and fibronectin complexes. It was thus difficult to determine whether the $28 \mathrm{kDa} \alpha_{1}-\mathrm{m}$ was liberated from the $\alpha_{1}-I_{3}$ or fibronectin complex. To overcome this problem, the $\alpha_{1}-\mathrm{m}$-fibronectin complex was isolated by pore-limit PAGE (Figure $4 \mathrm{a}$ ), and then analysed by SDS/PAGE under nonreducing or reducing conditions, followed by immunoblotting with anti- $\alpha_{1}-\mathrm{m}$ (Figure $4 \mathrm{~b}$ ). All $\alpha_{1}-\mathrm{m}$ was associated with highmolecular-mass bands around $200 \mathrm{kDa}$ when the separation was done without reducing agents (Figure $4 \mathrm{~b}$, lane 1), but dissociated completely in the presence of reducing agents (Figure $4 \mathrm{~b}$, lane 2 ). 
Table 1 Amounts of fibronectin and $\alpha_{1}-I_{3}$ in the eluates from anti- $\alpha_{1}-m$ affinity chromatography of plasma and serum from different rat strains

$\alpha_{1}-m$-containing proteins were purified from rat plasma or serum by anti- $\alpha_{1}-m$ affinity chromatography. The concentrations of fibronectin and $\alpha_{1}-I_{3}$ in the original plasma and serum samples (total) and in the eluates $\left(\alpha_{1}-m\right.$-bound) were determined by solid-phase r.i.a Abbreviations: SpD, Sprague-Dawley; WF, Wistar-Furth; Cop, Copenhagen.

\begin{tabular}{|c|c|c|c|c|c|c|}
\hline \multirow[b]{3}{*}{ Source } & \multicolumn{3}{|l|}{ Fibronectin } & \multicolumn{3}{|l|}{$\alpha_{1}-I_{3}$} \\
\hline & \multirow[b]{2}{*}{ Total $(g / l)$} & \multicolumn{2}{|c|}{$\alpha_{1}-m$-bound } & \multirow[b]{2}{*}{ Total $(g / l)$} & \multicolumn{2}{|c|}{$\alpha_{1}-m$-bound } \\
\hline & & $(\mathrm{mg} / \mathrm{l})^{\star}$ & $(\%)$ & & $(\mathrm{mg} / \mathrm{l})^{*}$ & $(\%)$ \\
\hline SpD plasma & 0.46 & 23 & 5.0 & 6.7 & 42 & 0.63 \\
\hline SpD serum & 0.36 & 25 & 7.0 & 8.0 & 59 & 0.74 \\
\hline WF plasma & 0.36 & 23 & 6.4 & 7.9 & 27 & 0.33 \\
\hline WF serum & 0.32 & 12 & 3.8 & 7.2 & 56 & 0.77 \\
\hline Cop plasma & 0.45 & 22 & 4.8 & 7.8 & 44 & 0.57 \\
\hline Cop serum & 0.34 & 12 & 3.6 & 7.8 & 49 & 0.62 \\
\hline
\end{tabular}

*The values for $\alpha_{1}-m$-bound fibronectin and $\alpha_{1}-I_{3}$ were adjusted to compensate for an $\alpha_{1}-m$ recovery of less than $100 \%$ in the affinity chromatography step.
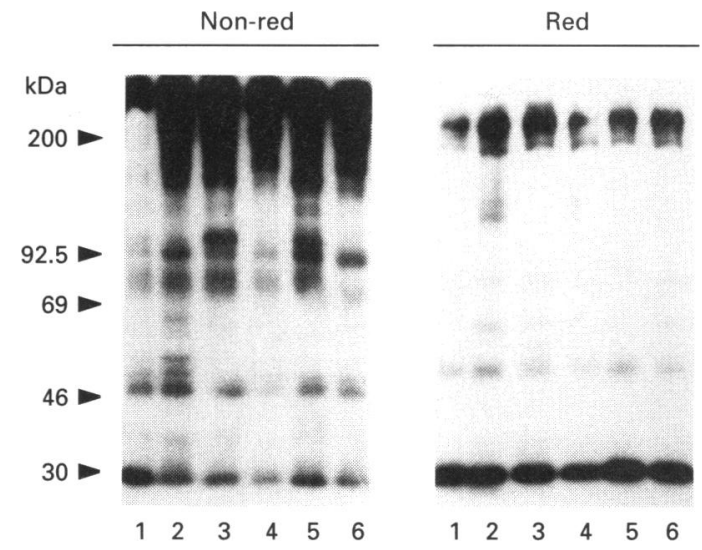

Figure 5 Comparison of $\alpha_{1}-m-$ containing proteins in plasma and serum from different rat strains

Plasma or serum from three different rat strains were subjected to affinity chromatography on an anti- $\alpha_{1}-m$ Affi-gel column. The proteins eluted with $0.1 \mathrm{M}$ glycine/ $\mathrm{HCl}, \mathrm{pH} 2.5$, were separated by SDS/PAGE ( $8.5 \%$ polyacrylamide, $2.5 \%$ bis-acrylamide) under non-reducing or reducing conditions. The proteins were then transferred to PVDF membranes, which were incubated with polyclonal rabbit anti- $\alpha_{1}-m$ antibodies and ${ }^{125}$-labelled goat anti-(rabbit lgG). Lane 1, Sprague-Dawley plasma was applied; lane 2, Sprague-Dawley serum; lane 3, Wistar-Furth plasma; lane 4, Wistar-Furth serum; lane 5, Copenhagen plasma; lane 6 Copenhagen serum.

This suggests that $\alpha_{1}-\mathrm{m}$ and fibronectin are linked together by disulphide bonds. The dissociated $\alpha_{1}-\mathrm{m}$ migrated upon SDS/PAGE as two bands, $28 \mathrm{kDa}$ and $58 \mathrm{kDa}$.

\section{$\alpha_{1}-m-$ fibronectin complex in plasma or serum from different rat strains and human plasma}

The two $\alpha_{1}-\mathrm{m}$ complexes were quantified in plasma and serum from three different rat strains. Small samples of plasma or serum were applied to anti- $\alpha_{1}-m$ affinity chromatography columns. No $\alpha_{1}-\mathrm{m}$ was found in the effluents from the column, as
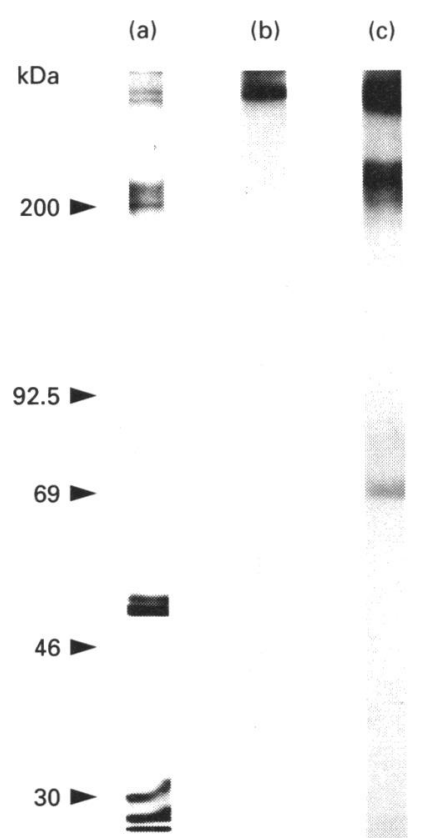

Figure 6 Western blotting of $\alpha_{1}-$ m-containing proteins in human plasma

Human plasma was subjected to affinity chromatography on an anti- $\alpha_{1}-\mathrm{m}$ Affi-gel column. The proteins eluted with $0.1 \mathrm{M}$ glycine/ $\mathrm{HCl}, \mathrm{pH} 2.5$, were separated by SDS/PAGE $(8.5 \%$ polyacrylamide, $2.5 \%$ bis-acrylamide) under non-reducing conditions. The gel was protein stained (a) or transferred to PVDF membranes, which were incubated with rabbit anti-(human $\alpha_{2}$-macroglobulin) (b) or anti-(human fibronectin) (c) and ${ }^{125}$-labelled goat anti-(rabbit lgG).

determined by r.i.a. The bound $\alpha_{1}-\mathrm{m}$ was eluted with $0.1 \mathrm{M}$

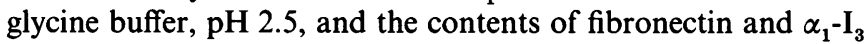
in the eluate and the original plasma or serum samples were estimated by solid-phase r.i.a. (Table 1). Thus approx. $0.3-0.8 \%$ of the plasma or serum $\alpha_{1}-I_{3}$ and $3-7 \%$ of the plasma or serum fibronectin was bound to the anti- $\alpha_{1}-\mathrm{m}$ column, presumably because of complex formation to $\alpha_{1}-\mathrm{m}$. No consistent differences were seen between the plasma and serum samples, or between different strains. In one set of experiments, the proteins eluted from the anti- $\alpha_{1}-\mathrm{m}$ affinity column were separated into highmolecular-mass and low-molecular-mass fractions by gel chromatograpy on Sephadex G-200. Approx. $60 \%$ of the total $\alpha_{1}-\mathrm{m}$ found by r.i.a. was in the high-molecular-mass fraction, and $40 \%$ in the low-molecular-mass fraction.

Some differences were observed when the plasma and serum samples were compared by SDS/PAGE (Figure 5). A band with an apparent mass of $115 \mathrm{kDa}$ was present in plasma samples but not in serum, and another band with an apparent mass of $165 \mathrm{kDa}$ was more pronounced in plasma than in serum. Furthermore, free monomeric $\alpha_{1}$-m dissociated from the highmolecular-mass bands when SDS/PAGE was performed in the presence of a reducing agent, supporting the finding that disulphide bonds are involved in the formation of the $\alpha_{1}$-m-fibronectin complex.

In an attempt to generalize the findings, human plasma was applied to an anti- $\alpha_{1}-\mathrm{m}$ affinity chromatography column. After washing, bound proteins were eluted with glycine buffer, $\mathrm{pH} 2.5$, analysed by SDS/PAGE under non-reducing conditions and blotted with anti-(human $\alpha_{2}$-macroglobulin) or anti-(human fibronectin) (Figure 6). Bands with apparent molecular masses 
$>400 \mathrm{kDa}$ were stained by anti- $\alpha_{2}$-macroglobulin and bands with apparent molecular masses of $>300 \mathrm{kDa}$ and $210 \mathrm{kDa}$ by anti-fibronectin, indicating the presence of $\alpha_{1}-\mathrm{m}-\alpha_{2}$-macroglobulin and $\alpha_{1}-\mathrm{m}$-fibronectin complexes respectively in human plasma.

\section{DISCUSSION}

This work describes the identification, isolation and partial characterization of a complex formed between the two plasma proteins $\alpha_{1}-\mathrm{m}$ and fibronectin. The $\alpha_{1}-\mathrm{m}$-fibronectin complex was isolated from rat plasma and characterized as a molecule with a mass of $500-600 \mathrm{kDa}$, which was stabilized by one or more disulphide bonds between the two proteins, and present in the circulation at approx. $20 \mathrm{mg} / 1$.

Another $\alpha_{1}$-m complex in rat plasma, formed with the protease inhibitor $\alpha_{1}-I_{3}$, was described in a previous report (Falkenberg et al., 1990). This complex appeared upon SDS/PAGE as several bands with molecular masses around $200-220 \mathrm{kDa}$ which react with antibodies against $\alpha_{1}-\mathrm{m}$ and $\alpha_{1}-\mathrm{I}_{3}$. The lack of detection of the $\alpha_{1}-m$-fibronectin complex during the purification of the $\alpha_{1}-m-\alpha_{1}-I_{3}$ complex is partly explained by the almost identical behaviour of the two complexes on SDS/PAGE under reducing conditions (Figure 3). However, anti- $\alpha_{1}-\mathrm{m}$ affinity chromatography of commercial rat plasma, which contained mostly degraded $\alpha_{1}-\mathrm{I}_{3}$ (not shown), revealed bands upon SDS/PAGE with molecular masses around $220 \mathrm{kDa}$ that did not react with $\alpha_{1}-I_{3}$, indicating a novel, non $-\alpha_{1}-I_{3}-\alpha_{1}-m$ complex. Elution of the $220 \mathrm{kDa}$ bands from the polyacrylamide gels, followed by protease digestion and purification of the resulting peptides by h.p.l.c., yielded sequences which were identical with those reported for rat fibronectin (see Hynes, 1990), suggesting that the novel complex was $\alpha_{1}-\mathrm{m}$-fibronectin. No sequences were achieved when analysing the bands before proteolytic cleavage, in accordance with reports from other investigators that the $\mathrm{N}$ termini of human fibronectin are blocked (Garcia-Pardo et al., 1983). The presence of another $\alpha_{1}-\mathrm{m}$ complex besides the $\alpha_{1}-I_{3}$ complex was also suggested by analysis of the anti- $\alpha_{1}-\mathrm{m}$ eluate by non-denaturing pore-limit PAGE. The identity of the complex as $\alpha_{1}-\mathrm{m}$-fibronectin was then confirmed with immunochemical methods.

It was estimated that $3-7 \%$ of total plasma or serum fibronectin was linked to $\alpha_{1}-\mathrm{m}$. An immunochemical competitive assay was used, and it was assumed that the $\alpha_{1}-\mathrm{m}$-fibronectin complex and free fibronectin interacted with anti-fibronectin antibodies on equal terms. The plasma and serum concentrations of fibronectin, 0.3-0.5 g/1, agreed well with reports from other investigators (Sochorova et al., 1983). In parallel, it was estimated that $0.3-0.8 \%$ of total plasma or serum $\alpha_{1}-\mathrm{I}_{3}$ was linked to $\alpha_{1}-\mathrm{m}$. The previously reported value of 1-3\% (Falkenberg et al., 1990) was probably in error because it was based upon a mixture of the $\alpha_{1}-I_{3}$ and fibronectin complexes. Our specific reason for examining differences between the plasma and serum distribution of $\alpha_{1}-\mathrm{m}$ relates to the possible ways in which the protein could incorporate into fibronectin and $\alpha_{1}-\mathrm{I}_{3}$. Blood coagulation converts plasma into serum by a proteolytic cascade system during which some fibronectin becomes covalently cross-linked to fibrin by the action of Factor XIII (Mosher, 1975). The proteinases active in this cascade are potentially able to activate the thiol ester of $\alpha_{1}-I_{3}$ and cause it to covalently incorporate proteins via their primary amino groups. If these events were responsible for incorporation of $\alpha_{1}-\mathrm{m}$, we should observe increased binding of $\alpha_{1}-\mathrm{m}$ to the two proteins by covalent links that do not involve disulphides. Although small structural differences were seen in
SDS/PAGE, no major quantitative differences were found in the distribution of $\alpha_{1}-\mathrm{m}$ between its binding proteins in plasma or serum. This rules out blood coagulation as a stimulation or mechanism of $\alpha_{1}-\mathrm{m}$ incorporation into fibronectin and $\alpha_{1}-I_{3}$.

Native fibronectin has been described as a heterodimer composed of two similar disulphide-linked polypeptides, each around $250 \mathrm{kDa}$ (for a review, see Mosher, 1992). The results in the present work are consistent with a model of the $\alpha_{1}-\mathrm{m}$-fibronectin complex in which the two fibronectin polypeptides and one or more of the $28 \mathrm{kDa} \alpha_{1}-\mathrm{m}$ polypeptides are interconnected by disulphide bonds. The calculated molecular mass of this model, $500-600 \mathrm{kDa}$ depending on the number of $\alpha_{1}-\mathrm{m}$ molecules, is consistent with the value for the isolated $\alpha_{1}-\mathrm{m}$-fibronectin complex, $560 \mathrm{kDa}$, achieved by gel chromatography. Larger values were obtained by pore-limit PAGE, $795 \mathrm{kDa}$ for $\alpha_{1}-\mathrm{m}-$ fibronectin and slightly less for uncomplexed fibronectin, most likely due to an elongated shape and low net charge of the molecules.

Fibronectin is described as a very fibrous molecule, with many structurally and functionally independent domains arranged in a linear fashion (for a review, see Hynes, 1990). To a large extent, the domains consist of homologous internal repeats of three types, I, II and III. Several protocols describe the isolation of such domains after proteolytic cleavage of the fibronectin molecule. Thus it should be possible to locate the $\alpha_{1}-\mathrm{m}$ molecule along the fibronectin polypeptide following proteolytic cleavage and isolation of $\alpha_{1}$-m-containing fragments. Assuming that the disulphide bond arrangement of rat $\alpha_{1}-\mathrm{m}$ is homologous to its human counterpart, rat $\alpha_{1}-\mathrm{m}$ has an unpaired cysteine residue at position 33 (Lindqvist et al., 1992). Obviously, this residue is a candidate for the disulphide interaction with fibronectin as it is not involved in an intra-chain disulphide loop. Each polypeptide of the fibronectin dimer has two free sulphydryl groups (Hynes, 1990), both of which are located in type III repeats, one near the middle and another near the C-terminal end of the polypeptide chain. Naturally, all four free sulphydryl groups of the fibronectin dimer are candidates for the binding of $\alpha_{1}-\mathrm{m}$. As mentioned in the introduction to this article, other circulating $\alpha_{1}-\mathrm{m}$ complexes have been described. Thus $\alpha_{1}-\mathrm{m}$ is found complexed to human albumin (Tejler and Grubb, 1976), human IgA (Grubb et al., 1986) and rat $\alpha_{1}-I_{3}$ (Falkenberg et al., 1990). Interestingly, all four complex partners have free sulphydryl groups. So far only $\alpha_{1}-\mathrm{m}$-fibronectin has been shown to be connected by disulphide bonds, and from a structural point of view it would be interesting to know if the other complexes are also joined via disulphide bonds, and if the complex partners of $\alpha_{1}-\mathrm{m}$ share a similar structure, primary or three-dimensional, around the bonds.

The site of formation of the $\alpha_{1}$-m-fibronectin complex is as yet unknown. To exclude the possibility that it was formed during the sample preparation or the purification procedure by an in vitro disulphide exchange between free sulphydryl groups on $\alpha_{1}-\mathrm{m}$ and fibronectin respectively, the rat blood was drawn in the presence of $N$-ethylmaleimide, which alkylates reactive sulphydryl groups. However, similar amounts of the $\alpha_{1}-\mathrm{m}-$ fibronectin complex could be purified under these conditions (not shown), indicating that the complex is formed in vivo. $\alpha_{1}-\mathrm{m}$, $\alpha_{1}-I_{3}$ and fibronectin are synthesized by hepatocytes (Tamkun and Hynes, 1983; Pierzchalski et al., 1992), and it could be suspected that the $\alpha_{1}-\mathrm{m}-\alpha_{1}-\mathrm{I}_{3}$ and $\alpha_{1}-\mathrm{m}$-fibronectin complexes are formed in these cells. However, no high-molecular-mass $\alpha_{1}-\mathrm{m}$ was detected in rat hepatocyte culture medium (Pierzchalski et al., 1992). To test whether the complexes are formed after the entry of $\alpha_{1}-\mathrm{m}$ into the vascular compartment, radiolabelled $28 \mathrm{kDa} \alpha_{1}-\mathrm{m}$ was incubated with rat plasma or serum, or was injected into the bloodstream of whole rats (not shown). No 
radiolabelled high-molecular-mass $\alpha_{1}$-m could be detected after anti- $\alpha_{1}-m$ affinity chromatography of the plasma or serum, contra-indicating vascular complex formation. However, an alternative explanation is that the free sulphydryl group of the $28 \mathrm{kDa} \alpha_{1}-\mathrm{m}$, which was purified from rat plasma, is more or less irreversibly blocked by unknown structures, as suggested by Escribano et al. (1991). Thus it can be speculated that in vivo, the $\alpha_{1}-m$ complexes are formed after secretion of free $\alpha_{1}-m$ into the bloodstream, but before blocking of the sulphydryl group by other structures.

The results in this study have interesting biological implications. $\alpha_{1}-\mathrm{m}$ regulates immune and inflammatory responses, and suppresses antigen-induced lymphocyte proliferation, granulocyte migration and chemotaxis (for a review, see Åkerström, 1992). Fibronectin binds to the extracellular matrix molecules collagen and heparin/heparan and to cell-surface integrin receptors, and acts as a ligand between cells and extracellular matrix during development and organization of tissues. It has binding sites for fibrin and is important for haemostasis and wound healing (Yamada, 1991). Hence, the discovery that 3-7\% of the fibronectin molecules carry $\alpha_{1}$-m suggests a mechanism for local immunoregulation during episodes such as wound healing and tissue morphogenesis.

We wish to thank Maria Allhorn and Carina Peratikou for excellent technical assistance, and Dr. Bo Cederholm for providing anti-(human fibronectin) and valuable advice. This work was supported by grants from the Swedish Medical Research Council (project no. 7144), King Gustav V's 80-year Foundation, the Medical Faculty at the University of Lund, the Swedish Society for Medical Research, the Royal Physiographic Society in Lund, and the Foundations of O. E. and Edla Johansson, Greta and Johan Kock, and Alfred Österlund.

\section{REFERENCES}

Åkerström, B. (1985) J. Biol. Chem. 260, 4839-4844

Åkerström, B. (1992) Folia Histochem. Cytobiol. 30, 183-186

Åkerström, B. and Lögdberg, L. (1990) Trends Biochem. Sci. 15, 240-243

Babiker-Mohamed, H., Åkerström, B. and Lögdberg, L. (1990) Scand. J. Immunol. 32, $37-44$

Babiker-Mohamed, H., Forsberg, M., Olsson, M. L., Winquist, 0., Lögdberg, L. and Åkerström, B. (1991) Scand. J. Immunol. 34, 655-666
Bratt, T., Olsson, H., Sjöberg, E. M., Fries, E., Jergil, B. and Åkerström, B. (1993) Biochim. Biophys. Acta 1157, 147-154

Bury, A. F. (1981) J. Chromatogr. 213, 491-500

Diarra-Mehrpour, M., Bourguignon, J., Sesboue, R., Salier, J. P., Leveillard, T. and Martin, J. P. (1990) Eur. J. Biochem. 191, 131-139

Ekström, B. and Berggård, I. (1977) J. Biol. Chem. 252, 8048-8057

Ekström, B., Peterson, P. A. and Berggård, I. (1975) Biochem. Biophys. Res. Commun. 65, $1427-1433$

Enghild, J. J., Thøgersen, I. B., Pizzo, S. V. and Salvesen, G. (1989) J. Biol. Chem. 264, 15975-15981

Enghild, J. J., Salvesen, G., Thøgersen, I. B., Valnickova, Z., Pizzo, S. V. and Hefta, S. A. (1993) J. Biol. Chem. 268, 8711-8716

Escribano, J., Grubb, A., Calero, M. and Mendez, E. (1991) J. Biol. Chem. 266. 15758-15763

Falkenberg, C., Grubb, A. and Åkerström, B. (1990) J. Biol. Chem. 265, 16150-16157

Falkenberg, C., Björck, L. and Åkerström, B. (1992) Biochemistry 31, 1451-1457

Fernandez-Luna, J. L., Levy-Cobian, F. and Mollinedo, F. (1988) FEBS Lett. 236, 471-474

Garcia-Pardo, A., Pearlstein, E. and Frangione, B. (1983) J. Biol. Chem. 258, 12670-12674

Greenwood, F. C., Hunter, W. M. and Glover, J. S. (1963) Biochem. J. 89, 114-123

Grubb, A., Mendez, E., Fernandez-Luna, J. L., Lopez, C., MihaesCo, E. and Vaerman, J.-P. (1986) J. Biol. Chem. 261, 14313-14320

Hunkapiller, M. W., Lujan, E., Ostrander, F. and Hood, L. E. (1983) Methods Enzymol. 91, $227-236$

Hynes, R. O. (1990) Fibronectin, Springer, New York

Kaumeyer, J. F., Polazzi, J. O. and Kotick, M. P. (1986) Nucleic Acids Res. 14, 7839-7850 Laemmli, U. K. (1970) Nature (London) 227, 680-685

Lindqvist, A., Bratt, T., Altieri, M., Kastern, W. and Åkerström, B (1992) Biochim. Biophys. Acta 1130, 63-67

Lögdberg, L. and Åkerström, B. (1981) Scand. J. Immunol. 13, 383-390

Madsudaira, P. (1987) J. Biol. Chem. 262, 10035-10038

Manwell, C. (1977) Biochem. J. 165, 487-495

Mendez, E., Fernandez-Luna, J. L., Grubb, A. and Levy-Cobian, F. (1986) Proc. Natl. Acad. Sci. U.S.A. 83, $1472-1475$

Mosher, D. F. (1975) J. Biol. Chem. 250, 6614-6621

Mosher, D. F. (1992) in Human Protein Data (Haeberli, A., ed.), VCH, Weinheim Nilson, B., Björck, L. and Åkerström, B. (1986) J. Immunol. Methods 91, 275-281 Pierzchalski, P., Rokita, H., Koj, A., Fries, E. and Åkerström, B. (1992) FEBS Lett. 298, 165-168

Rouet, P., Daveau, M. and Salier, J. P. (1992) Biol. Chem. Hoppe-Seyler 373, 1019-1024 Salier, J.-P. (1990) Trends Biochem. Sci. 15, 435-439

Sochorova, L., Deyl, Z. and Michl, J. (1983) Physiol. Bohemoslov. 32, 481-485

Tamkun, J. W. and Hynes, R. 0. (1983) J. Biol. Chem. 258, 4641-4647

Tejler, L. and Grubb, A. O. (1976) Biochim. Biophys. Acta 439, 82-94

Vetr, H. and Gebhard, W. (1990) Biol. Chem. Hoppe-Seyler 371, 1185-1196

Yamada, K. (1991) in Cell Biology of Extracellular Matrix (Hay, E. D., ed.), 2nd edn., pp.

111-124, Plenum Press, New York

Received 1 December 1993/14 February 1994; accepted 4 March 1994 